\title{
Health Services Researchers Working within Healthcare Organizations: The Intriguing Sound of Three Hands Clapping
}

\section{Les chercheurs au sein des organismes de services de santé}

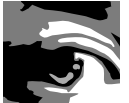 \\ by ROGER CHAFE AND MARK DOBROW \\ Cancer Services and Policy Research Unit \\ Cancer Care Ontario \\ Department of Health Policy, Management $\mathcal{E}$ Evaluation \\ University of Toronto \\ Toronto, ON
}

\begin{abstract}
Healthcare organizations offer a promising but complicated work environment for health services researchers. Working directly within these organizations can yield stronger connections with decision-makers, better access to organizational data and, ultimately, greater potential for research findings to influence decisions. However, there are also challenges for the researcher and the host organization related to divergent work objectives, mismatched timelines and unclear criteria for performance assessment. The authors examine the advantages and disadvantages of this research model for both the health services researcher and the decision-maker.
\end{abstract}




\section{Résumé}

Les organismes de santé représentent des milieux de travail prometteurs, bien que complexes, pour les chercheurs qui s'intéressent aux services de santé. En travaillant directement au sein de ces organismes, les chercheurs peuvent établir des liens plus forts avec les décideurs et accéder plus facilement aux données. Leurs résultats ont également plus de chances d'influer sur les décisions. Toutefois, les chercheurs comme les organismes font face à des défis quant aux objectifs de travail divergents, aux échéanciers incompatibles et aux critères imprécis en matière d'évaluation du rendement. Les auteurs examinent les avantages et les désavantages de ce modèle de recherche, tant pour les chercheurs que pour les décideurs.

\footnotetext{
Dor the last decade or more, researchers and decision-makers in Canada have been actively trying to break down the walls that have separated Lealth services researchers from healthcare providers, managers and policy
} makers (Lomas 1997; CHSRF 2007). There has been focused examination on the nature of researcher/decision-maker partnerships (Denis and Lomas 2003; Denis et al. 2003; Ross et al. 2003; Martens and Roos 2005), their impact on the uptake of research by decision-makers (Innvaer et al. 2002; Lavis et al. 2002) and the structures and processes that facilitate or impede these interactions (Ross et al. 2003; Mitton and Bate 2007; Martens and Roos 2005).

One of the consequences of this push to bring decision-makers and researchers closer together is that it is becoming more common for health services researchers to work directly within healthcare organizations. Some examples of Canadian healthcare organizations directly employing researchers include the British Columbia Cancer Agency's Health Economics and Cancer Research Program, Cancer Care Ontario's Cancer Services and Policy Research Unit, the Centre for Addiction and Mental Health's Health Systems Research and Consulting Unit and health services/policy research units in a number of regional health authorities (e.g., the Calgary Health Region and Eastern Health in Newfoundland and Labrador). However, the implications of this research model are not always clear for either health services researchers or the organizations in which they work.

In this paper, we look at some of the advantages and disadvantages of this type of research position, primarily based on our own experiences as researchers who currently work within this research context. Although the nature of these positions varies from organization to organization, our experience will likely resonate with others working in similar situations. We conclude by identifying issues requiring further consideration and make some recommendations on how to maximize the benefits of this increasingly common research arrangement. 


\section{Defining the Role}

Traditionally, health services research has been conducted by university-based researchers or researchers working in dedicated research institutes. Many healthcare providers, in addition to their clinical responsibilities, have also been engaged in health services research. However, we are focusing here on those health services researchers (a) who are embedded within organizations that have responsibility for the organization or delivery of health services (e.g., government ministries or agencies responsible for health services, regional health authorities, hospitals and other provider organizations) and (b) whose primary responsibility is to develop and lead independent health services research.

We view a key feature of being a health services researcher, regardless of setting, as the intent to produce work that is useful beyond a particular organization and the desire to disseminate research findings to audiences beyond that organization. Much of the tension associated with health services researchers working directly within a healthcare organization relates to this dual focus - supporting decision-making within a specific organization, but also producing work that will be valuable to those outside it (and, hopefully, publishable as well).

\section{Interactions with Decision-Makers}

One of the proposed ways to improve research uptake is to have early and regular interaction between researchers and decision-makers (Lomas 2000; Lavis et al. 2002). Working directly within a healthcare organization allows for a greater level of interaction with policy makers, managers, clinicians and clinical leaders than can usually be maintained by researchers who are based outside these organizations. Regular opportunities to participate in organizational meetings and activities, discuss organizational challenges and consider prospective research questions with decision-makers gives the researcher based in a healthcare organization a better understanding of the decisionmaking context and extends the researcher/decision-maker relationship beyond the confines of individual research projects (Ross et al. 2003).

Established connections with decision-makers can improve access to organizational data. The identification of data sources and the ability to secure timely organizational approval for data access facilitates proposal development and the conduct of research. The decision-makers themselves represent key qualitative data sources. Their existing relationships with in-house health services researchers creates a natural context for data collection via key-informant interviews or focus groups.

While having greater access to decision-makers, health services researchers based in healthcare organizations will likely have less interaction with academic colleagues and students. This potential disadvantage is mitigated to some extent if the researcher holds an academic appointment or has academic responsibilities (e.g., teaching or supervi- 
sion of graduate students). From a healthcare organization's perspective, one of the advantages of having health services researchers on staff is that they can be an excellent conduit for connecting with the external health services research community. These connections can be important for bringing new knowledge into the organization and fostering innovation.

Healthcare organizations must also consider whether developing internal health services research capacity is a wise use of scarce resources. Ongoing interaction between researchers and decision-makers may broaden the scope of research questions addressed and identify research opportunities that support decision-making within the organization. However, decision-makers face the fine balance between influencing the research questions pursued and biasing the direction of the research or its outcomes. As researchers in healthcare organizations often report to a senior decision-maker, the freedom to pursue an independent research agenda depends, then, to a much larger extent than in other research environments, on the degree of independence the decision-maker provides to the researcher. The nature of these freedoms can be, but are often not, explicitly framed through contractual agreements between healthcare organizations and embedded researchers, as is done for broader relationships between healthcare organizations and external health services researchers (Martens and Roos 2005).

\section{Research Funding and Infrastructure}

The ability to secure funding is critical for maintaining a high-quality and sustainable research program. Many of the main Canadian health services research funding agencies (e.g., Canadian Institutes of Health Research, Canadian Health Services Research Foundation and Canadian Patient Safety Institute) are increasingly encouraging researcher/decision-maker collaboration in targeted funding competitions. For example, the CIHR Partnerships grant competition requires applicants to bring together a team of researchers and decision-makers, with decision-making organizations committed to matching funds dollar for dollar (CIHR 2007). Health services researchers working within healthcare organizations are well positioned to compete in these funding competitions and provide an important link to external funds for healthcare organizations that want to pursue strategic issues that might not otherwise receive attention.

These same funding programs also expose one of the most critical barriers to collaborative work between health services researchers and decision-makers: the mismatch in timelines between the typical research cycle and decision-makers' needs (Lomas 2000). Major research funding competitions often require between six months and one year from initial submission to the awarding of funds to successful applicants. With decision-making often a sprint, and research a journey, this lag can create difficulties for researcher/decision-maker collaborations that do not anticipate the mismatch in timelines. Health services researchers embedded in healthcare 
organizations must actively work with decision-maker colleagues to set out realistic expectations for research outputs that can inform decision-making, usually over the medium to long term (Black 2001).

\section{Methodological Rigour and Research Ethics}

The time required to conduct research depends, to some degree, on the level of rigour required. For decision-makers, it is often more important to produce work quickly, increasing its relevance for issues that are currently on the organization's agenda. Healthcare organizations often hire external consultants to conduct program evaluations in relatively tight timeframes, often at the expense of methodological rigour. Researchers, on the other hand, require a higher degree of rigour, especially if they intend to disseminate their work to wider audiences (e.g., in peer-reviewed journals). Ensuring the appropriate level of methodological rigour takes time. Health services researchers in healthcare organizations can often face the dilemma of needing to provide timely, relevant research results to their organizational decision-maker colleagues, while at the same time attempting to meet the methodological expectations of the wider research community. Embedded researchers may often be involved in projects that solely support organizational objectives; however, this work lies in a grey zone regarding the need for ethics approval, timeliness relative to organizational demands and the potential acceptability by peer-reviewed publications.

Other issues related to research ethics arise because of the researcher's position within the organization they are often studying. While in other fields, most researchers do not have direct reporting relationships with study subjects, health services researchers based in healthcare organizations often have such links. As many new funding opportunities require decision-maker involvement in research projects, the traditional assurance of confidentiality or anonymity given to study subjects can be complicated. Researchers and decision-maker partners need to establish at the outset of a project who will be allowed to view raw data, particularly identifiable data from interviews of other decision-maker colleagues, and their respective contributions to the analysis, so that study participants can provide informed consent. However, the potential need to restrict the role of decision-makers in the analysis of data can sometimes negate the critical insights that decision-makers can bring to this research arrangement.

Beyond concerns of confidentiality and anonymity, health services researchers based in healthcare organizations regularly produce results that are linked, directly or indirectly and either positively or negatively, to the efforts of their decision-maker colleagues. While there are high-profile cases of industry and institutional influence over the dissemination of research results (Thompson et al. 2001), there are more implicit and intangible ways for decision-makers to influence research. While external funding sources and ethics review processes can facilitate proper conduct, there may be subtle 
internal pressures that influence or bias the publication of negative findings to which researchers working in this context need to be attuned.

\section{Assessing Performance}

Another aspect of the research context that differs considerably between universities or research institutes and healthcare organizations is the assessment of performance of health services researchers. In traditional academia, the tenure-track model guides performance reviews, which value scientific success and output (mostly based upon peer-reviewed grants and publications) and teaching performance as key elements in assessments for promotion. For health services researchers in healthcare organizations, the assessment of performance is less clear.

Because many health services researchers hold academic appointments and also work in healthcare organizations, they essentially report to two masters. While Mitton and Bate (2007) have suggested that reward structures for university-based applied researchers do not require fundamental reform, health services researchers based in healthcare organizations face a different set of intrinsic and extrinsic incentives that expose misalignments between specific organizational objectives and traditional academic aims.

Closely linked to the confusion over performance review, differences in pay scales in healthcare organizations versus universities create further uncertainty. Should the health services researcher working for a healthcare organization be paid based on pay scales for a relevant university department or on the employing organization's scales? When the scales are similar, there are fewer issues; however, when the scales differ significantly, there may be expected but unintended consequences. For example, higher pay scales in a healthcare organization may influence the health services researcher to shift roles and take on more decision-making responsibilities, while higher pay scales in the university department may influence the researcher to give academic performance greater priority. If health services researchers become more prevalent in healthcare organizations, the impact of remuneration models requires greater consideration.

\section{Moving Forward}

Health services researchers working within healthcare organizations create a complex but potentially synergistic environment in which health services research can flourish. In Table 1, we set out some of the key advantages and disadvantages of this research model.

To maximize the benefits of this arrangement, there are a number of measures that could further support health services researchers embedded in healthcare organizations. First, health services research funders need to continue to develop funding opportunities that explicitly recognize and encourage researchers based in healthcare organiza- 
tions. Expansion of partnership grants creates excellent opportunities for embedded researchers, while salary support programs, such as Ontario's Career Scientist Awards (OMHLTC 2008) or those offered by the Michael Smith Foundation for Health Research (2008), make this model more appealing to healthcare organizations (by reducing salary costs) and researchers (by providing more opportunities to improve performance based on academic criteria). Second, contractual agreements between healthcare organizations and their embedded health services researchers should be enhanced. These contracts need to define the researcher's role and explicitly establish the researcher's academic freedom to conduct research and disseminate findings. The contracts should also clearly set out criteria for performance assessment and remuneration that acknowledge contributions to the organization beyond the scope of traditional academic performance assessment. Third, ethics review boards need to address the implications of this embedded research model, including development of clearer criteria for the types of research that require ethics review, and guidance for the role that decision-makers can or should play in the conduct of research. Finally, given the emergent nature of this type of health services research position, there is much to learn from those currently working in this context. Greater efforts are needed to document and compare the experiences of others in similar positions, both in Canada and internationally, to improve the potential of this research model.

TABLE 1. Advantages and disadvantages of health services researchers working within healthcare organizations

\begin{tabular}{|c|c|c|}
\hline & Advantages & Disadvantages \\
\hline For decision-makers & $\begin{array}{l}\text { - Increased interaction with researchers } \\
\text { - Allows decision-makers easy access to } \\
\text { researchers to support decision-making } \\
\text { - Conduit for interactions with external } \\
\text { health services research expertise } \\
\text { - Helps foster innovation } \\
\text { - Allows development of a more relevant } \\
\text { research agenda } \\
\text { - Greater potential for research findings to } \\
\text { influence decision-making } \\
\text { - Greater potential to draw on external } \\
\text { research funding sources to support } \\
\text { organization objectives }\end{array}$ & $\begin{array}{l}\text { - Resources for researchers may be used for } \\
\text { some projects that are not specifically focused } \\
\text { on the organization } \\
\text { - Researchers' timelines are often too long to } \\
\text { be useful for decision-makers } \\
\text { - Requires organizational resources that could } \\
\text { be used for other purposes, including service } \\
\text { provision }\end{array}$ \\
\hline $\begin{array}{l}\text { For health services } \\
\text { researchers }\end{array}$ & $\begin{array}{l}\text { - Increased interaction with decision-makers } \\
\text { - Allows development of a more relevant } \\
\text { research agenda } \\
\text { - Greater potential for research findings to } \\
\text { influence decision-making } \\
\text { - Facilitates development of researcher/ } \\
\text { decision-maker collaborations required for } \\
\text { many grant funding competitions } \\
\text { - Facilitates access to organizational data } \\
\text { sources }\end{array}$ & $\begin{array}{l}\text { - Less control over research agenda } \\
\text { - Dilemma between methodological rigour } \\
\text { appropriate for academic audiences and } \\
\text { relevance/timeliness for decision-maker } \\
\text { audiences } \\
\text { - Involvement of decision-makers in research } \\
\text { projects can result in more complex research } \\
\text { ethics contexts } \\
\text { - Confusion around performance assessment }\end{array}$ \\
\hline
\end{tabular}


Jonathan Lomas' "one hand clapping" paper (1997) was a rallying cry for greater interaction between researchers and decision-makers. A decade later, there appears to have been some movement. The sound of one hand clapping has become intriguingly audible, with the hands of health services researchers, academia and a range of decisionmaking organizations attempting to join in. However, while we are moving in the right direction, it is still too early for an ovation. With interest in health services research greater than ever before, more funding opportunities mean more research projects and more health services research positions (Hutchison 2007). Ultimately, the success of researchers working directly within healthcare organizations will depend on the commitment and cooperation of health services researchers, healthcare organizations, funders, universities, ethics review boards and other stakeholders. We now have important opportunities to structure these relationships to ensure that this model of health services research delivers on its promise.

Correspondence may be directed to: Roger Chafe, Cancer Care Ontario, 620 University Avenue, Toronto, ON M5G 2L7; tel.: 416-971-9800, ext. 3232; e-mail: roger.chafe@cancercare.on.ca.

\section{REFERENCES}

Black, N. 2001. “Evidence Based Policy: Proceed with Care." British Medical Journal 323: 275-79. Canadian Health Services Research Foundation (CHSRF). 2007. Knowledge Exchange. Resources. Retrieved September 30, 2008. <http://www.chsrf.ca/knowledge_transfer/resources_e.php>. Canadian Institutes of Health Research (CIHR). 2007. Partnerships for Health System Improvement. Retrieved September 30, 2008. <http://www.cihr-irsc.gc.ca/e/34347.html>.

Denis, J.L., P. Lehoux, M. Hivon and F. Champagne. 2003. “Creating a New Articulation between Research and Practice through Policy? The Views and Experiences of Researchers and Practitioners." Journal of Health Services Research and Policy 8(S2): 44-50.

Denis, J.L. and J. Lomas. 2003. “Convergent Evolution: The Academic and Policy Roots of Collaborative Research." Journal of Health Services Research and Policy 8(S2): 1-6.

Hutchison, B. 2007. “Divvying Up the Funding Pie: What Share for Health Services and Policy Research?" Healthcare Policy 2(4): 12-16.

Innvaer, S., G. Vist, M. Trommald and A. Oxman. 2002."Health Policy-Makers' Perceptions of Their Use of Evidence: A Systematic Review." Journal of Health Services Research and Policy 7(4): 239-44.

Lavis, J.N., S.E. Ross, J.E. Hurley, J.M. Hohenadel, G.L. Stoddart, C.A. Woodward and J. Abelson. 2002. "Examining the Role of Health Services Research in Public Policymaking." Milbank Quarterly $80(1): 125-54$. 
Lomas, J. 1997. Improving Research Dissemination and Uptake in the Health Sector: Beyond the Sound of One Hand Clapping. Hamilton, ON: McMaster University Centre for Health Economics and Policy Analysis, Policy Commentary C97-1. Retrieved September 30, 2008. <http://www.chsrf. ca/knowledge_transfer/pdf/handclapping_e.pdf $>$.

Lomas, J. 2000. “Connecting Research and Policy." Canadian Journal of Policy Research 1(1): 140-44.

Martens, P. and N. Roos. 2005. "When Health Services Researchers and Policy Makers Interact: Tales from the Tectonic Plates." Healthcare Policy 1(1): 72-84.

Michael Smith Foundation for Health Research. 2008. Career Investigator Program. Retrieved September 30, 2008. <http://www.msfhr.org/sub-funding-career.htm>.

Mitton, C. and A. Bate. 2007. "Speaking at Cross-Purposes or Across Boundaries?" Healthcare Policy 3(1):32-37.

Ontario Ministry of Health and Long-Term Care (OMHLTC). 2008. Research Competitions. Retrieved September 30, 2008. <http://www.health.gov.on.ca/english/providers/ministry/ research/competitions.html>.

Ross, S., J. Lavis, C. Rodriguez, J. Woodside and J.L. Denis. 2003. "Partnership Experiences: Involving Decison-Makers in the Research Process." Journal of Health Services Research and Policy 8(S2): 26-34.

Thompson, J., P. Baird and J. Downie. 2001. Report of the Committee of Inquiry on the Case Involving Dr. Nancy Olivieri, the Hospital for Sick Children, the University of Toronto, and Apotex Inc. Ottawa: Canadian Association of University Teachers.

\section{Call to Authors}

\section{DISCUSSION AND DEBATE}

The Discussion and Debate section of Healthcare Policy offers a forum for essays and commentaries that address: (1) important health policy or health system management issues; or (2) critical issues in health services and policy research. Submissions should be a maximum of 2,000 words exclusive of (no more than 20) references. The main points of the paper should be highlighted in an abstract (summary) of 100 words or less.

\section{Appel aux auteurs}

DISCUSSIONS ET DÉBATS

La section «Discussions et débats » de Politiques de Santé offre un forum pour la publication de comptes rendus et de commentaires portant sur les sujets suivants : (1) d'importantes questions liées aux politiques de santé ou à la gestion du système de soins de santé; ou (2) des questions cruciales concernant les services de santé et la recherche sur les politiques. Les articles devraient être d'au plus 2000 mots, sans compter les références (pas plus de 20). Les points saillants de l'article devraient être mis en évidence dans un résumé (sommaire) de 100 mots ou moins.

For more information contact Ania Bogacka, Managing Editor, at abogacka@longwoods.com. Pour de plus amples renseignements, veuillez communiquer avec Ania Bogacka, Directrice de rédaction, à abogacka@longwoods.com. 